\title{
Numerical simulation of indirect heating of water by heat transfer surface area located at the heat source
}

\author{
K. Kaduchová ${ }^{1, a}$, R. Lenhard ${ }^{1}$, S. Gavlas ${ }^{1}$, and J. Jandačka ${ }^{1}$ \\ ${ }^{1}$ University of Žilina, Faculty of Mechanical Engineering, Department of Power Engineering, Univerzitna 1, \\ 01026 Žilina, Slovakia
}

\begin{abstract}
Heating the water in the water tank indirectly heated water runs through the heat exchange surfaces heated by the heat source. Using mathematical modeling for indirect heating of water in the water tank was determined heating time for the selected heat exchange surface. The results obtained were compared to the 3D numerical simulation. The results of the simulations is then investigated the variation of a mathematical model to numerical simulation. The results have not yet experimentally verified on real equipment.
\end{abstract}

\section{Introduction}

Fireplace inserts are finished furnace with adjustable air supply, with glass doors and direct outlet burnt gas in the chimney. They stand in a room alone, or may be incorporated into sheath the fireplace. Part of the heat produced from the fireplace insert is transmitted by radiation, mainly through the glass doors and part of the convection air heating. Fireplace inserts are made either as a grate or without grid and material the fireplace inserts is either steel or cast iron. For heating smaller spaces such as huts, respectively smaller spaces can be used fireplace inserts with built-in hot-water heat exchanger, which heats the heating water. Then some of the heat used to warm air heating especially the space in which the fireplace and some heat is used for hot water heating adjacent rooms with heaters.

\section{Heating of hot water in small heat sources to biomass using heat pipes}

Another way to use the fireplace insert for heating hot water is using heat pipe. Heat pipes are hermetically of sealed tubes, suitably filled with working medium, such is antifreeze, water, and alcohol. Heat pipes are installed one end of the up chimney, which not affect the combustion in fireplace and it is utilized outgoing heat up the chimney fireplace insert. The other end of the heat pipe is embedded as a fired heat exchanger to heat hot water tank, where it releases its heat.

Principle of heat pipe:

Heat pipe through the burnt gas at one side is heated, it causes the end of the heating side tube will start working medium in heat pipe evaporate. Subsequently, the steam passes through the tube to the cold end, which is embedded in a hot water heating tank, here condensed prior back into liquid and gravity flow goes back to the warm end, where it evaporates again. This raises the circulation of working medium associated with the transfer of heat to the temperature difference.

\subsection{Hot water heat exchanger of the fireplace inserts}

In this case, hot water heat exchanger mounted in the hearth, or to the flue tile liner. The advantage of this arrangement is that the exchanger does not affect the burning in the fireplace, while the residual heat is utilized to the outgoing to chimney. Used to several ways to transfer heat from the flue gas to heating water. Efficiency transport heat can be achieved by appropriate arrangement of heat transfer surface area, or an appropriate ribbing their surfaces.

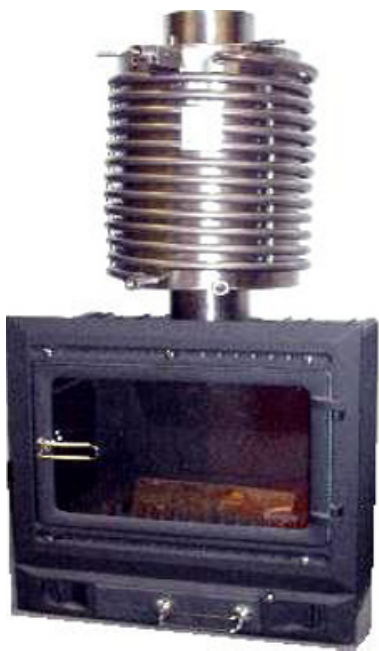

Fig. 1. Hot water heat exchangers of the fireplace insert.

akatarina.kaduchova@fstroj.uniza.sk 


\section{Experimental device}

The experimental device consists of a heat source, heat exchange area and water boiler. The experimental measurements are used as heat fireplace insert type "HT BRILANT900 $\mathrm{H}$ figure 2 rated output was determined by measurement. On a given experimental device measurements were carried out in accordance with European standard EN 13229 "Built-in heating appliances and fireplaces for solid fuel": nominal heat output, minimum heat output, resumption of the combustion process, and safe operation.

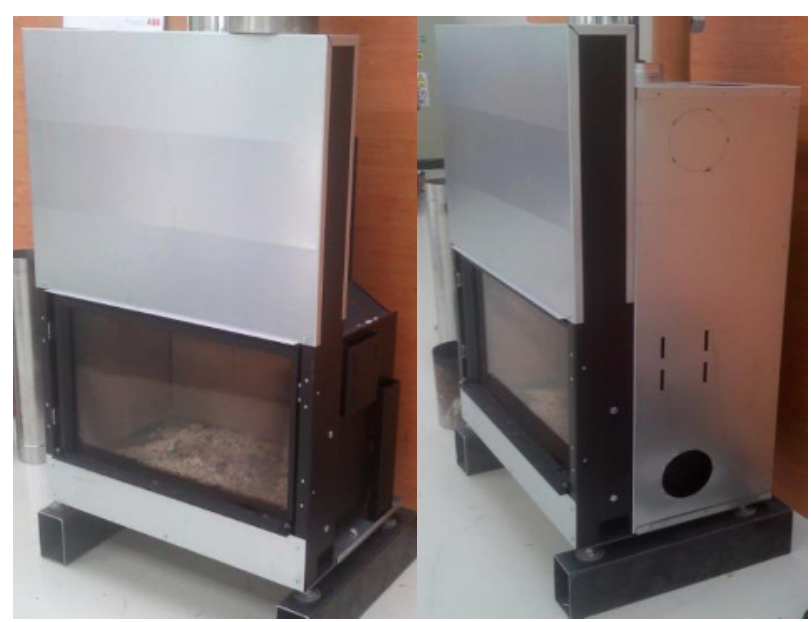

Fig. 2. Fireplace insert.

By measuring the fireplace insert type HT BRILANT $900 \mathrm{H}$ figure 2 was measured:

- The average rated power: $10.41 \mathrm{~kW}$.

- Average temperature of fuel: $197.77^{\circ} \mathrm{C}$.

- The average temperature of the test room: $23.05^{\circ} \mathrm{C}$.

On the basis of measured values is carried out experimental calculations on mathematical modeling and subsequently carried out using computer simulation, experimental program Fluent.

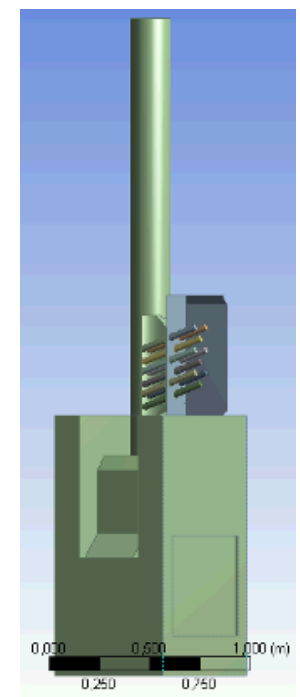

Fig. 3. Simplified 3D model.

In figure 3 shows 3D geometry fireplace insert type HT BRILANT $900 \mathrm{H}$ and location of the heat exchange surfaces of the tube, respectively flue gas heat source and the reservoir water.

This geometry is used for other experimental numerical simulations, which will investigate the impact of all components of the experimental device. For our numerical simulations of the simplified 3D model figure 3. As a test type heat exchange surfaces of the chose closed tube figure 5."This is a gravity heat pipe" because of what the simplest manufacturability. The experimental numerical calculation using an empty tube for further experimental calculations, these tubes will carry out table 1 , and will be experimentally detected, of which content is best suited for this type of water heating.

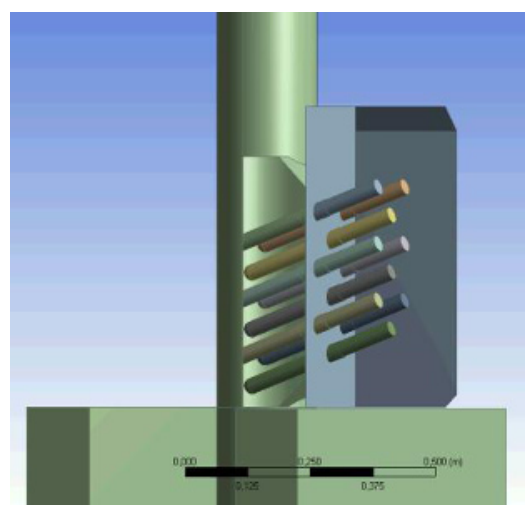

Fig. 4. Simplified 3D model - detail.

Geometrical parameters of the selected heat exchanging surface:

- Material: Copper.

- Length: $300 \mathrm{~mm}$.

- Diameter: $32 \mathrm{~mm}$.

- Number: 9 pcs.

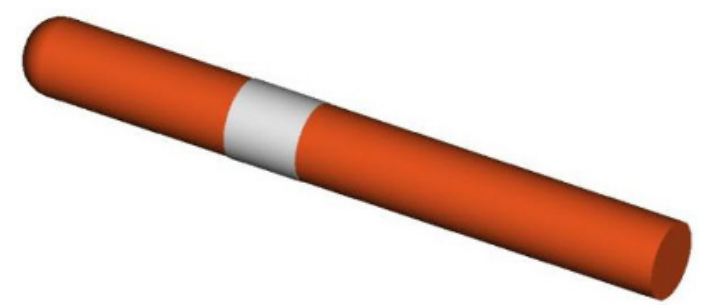

Fig. 5. Selected heat exchanging surface.

Table 1. List of selected other possible working fill.

\begin{tabular}{|c|c|c|c|}
\hline $\begin{array}{c}\text { Working } \\
\text { fill }\end{array}$ & $\begin{array}{c}\text { Working } \\
\text { area } \\
\left({ }^{\circ} \mathbf{C}\right)\end{array}$ & $\begin{array}{c}\text { Boiling } \\
\text { point } \\
\left({ }^{\circ} \mathbf{C}\right)\end{array}$ & $\begin{array}{c}\text { Freezing point at } \\
\text { atmospheric } \\
\text { pressure }\left({ }^{\circ} \mathbf{C}\right)\end{array}$ \\
\hline Water & $\begin{array}{c}30 \text { up to } \\
200\end{array}$ & 100 & 0 \\
\hline Ethanol & $\begin{array}{c}0 \text { up to } \\
130\end{array}$ & 78 & -112 \\
\hline Methanol & $\begin{array}{c}10 \text { up to } \\
130\end{array}$ & 64 & -98 \\
\hline Acetone & $\begin{array}{c}0 \text { up to } \\
120\end{array}$ & 57 & -95 \\
\hline
\end{tabular}




\subsection{The mathematical model}

Mathematical model for water heating has been identified, the time for us to heat up the required volume of water in the boiler indirectly heated by heat transfer surface area located in the heat source with a heating area of $0.27 \mathrm{~m}^{2}$.

Heating time:

Heating time was determined under these conditions, when used in heat exchange surface boils water in $15^{\circ} \mathrm{C}$ to $60{ }^{\circ} \mathrm{C}$ required to boiler volume of 55 liters with an estimated $80 \%$ heating efficiency.

Demand for energy $E$ :

$$
E=m_{v} \times c_{W h} \times\left(t_{1}-t_{2}\right)
$$

Heat output water heater $Q$ :

$$
Q=\frac{1}{\eta} \times \frac{E}{\tau}
$$

Heating time $\tau$ :

$$
\tau=\frac{E}{Q \times \eta} \times 60 \quad(\min )
$$

Heating time $\tau$ for the type of boiler with a specified number of heat pipes is $175 \mathrm{~min}$. The result of mathematical simulation in heat water in the tank indirectly heated water through the heat exchange surfaces placed in a heat source are compared from numerical simulation and found it is sufficiently large heat exchange area for hot water at $60^{\circ} \mathrm{C}$ with an estimated $85 \%$ efficiency.

\section{Numerical simulation of boiler for water heating using the heat transfer surface area}

Numerical models figure 6 were developed on the basis of a real model.

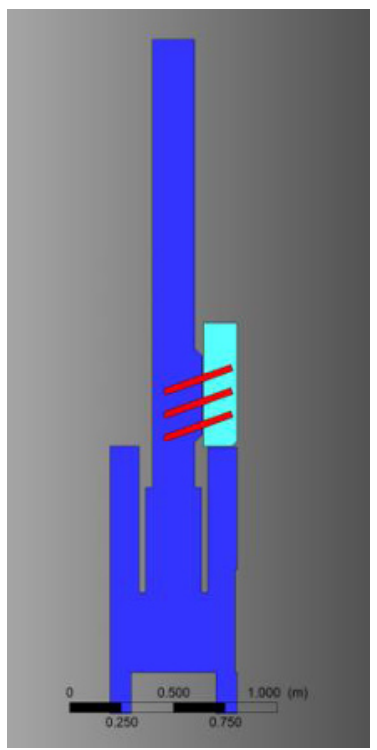

Fig. 6. Cut of 3D geometric numerical model.

The Geometry model was created in the Workbench program according to already designed construction. After meshed has been given as a model for boundary zones (where geometry is fluid, solid and where is an input and an output). Thus formed was transferred to a model simulation Fluent program.

Fluent program is commonly used CFD software, which defines boundary conditions that are understood as a precondition for the correct calculation. The Turbulent and Laminar model was because of the heat pipe heat is transferred laminar flow and when water heating also occurs through the natural flow. The Turbulent model was as two - equations $\mathrm{k}-\varepsilon$. This is the most widely tested and used a two- equation -transport- model (two transport equations for $\mathrm{k}$ and $\varepsilon$ ). The $\mathrm{k}-\varepsilon$ model generally gives good results in simple flows as far as the means of the velocities and energies are concerned.

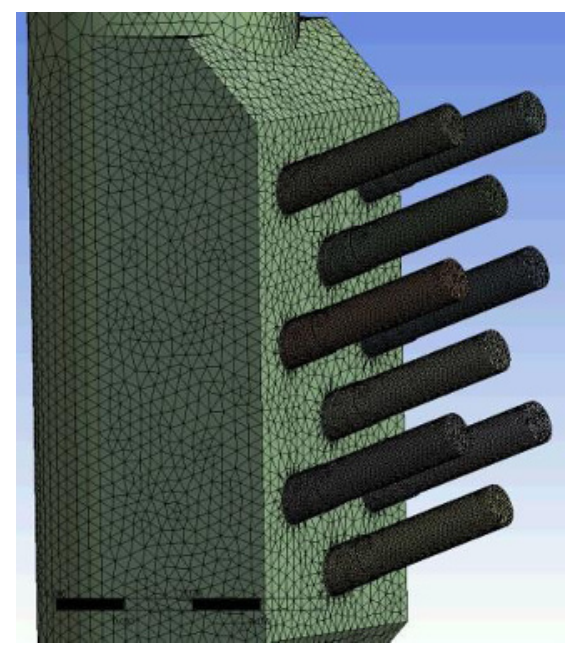

Fig. 7. Detail of mesh 3D geometric numerical model.

Simulations were conducted for the following input conditions which were intake from measuring:

- Heating time for accumulation heat into the boiler from mathematical model.

- Flue gas temperature and ambient.

- Shell conduction for intakes heat to the water.

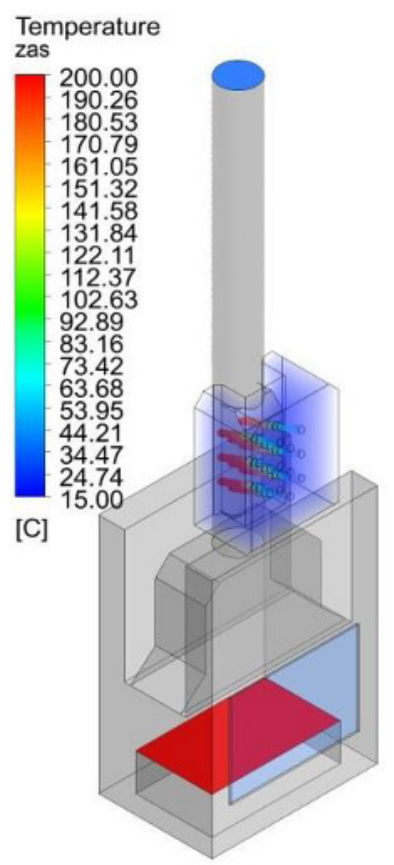

Fig. 8. Results from CFD simulation after $175 \mathrm{~min}$. 
Results from numerical simulation:

On figure 8 and figure 9 is shown results from CFD simulation after $175 \mathrm{~min}$. With this simulation do not achieved expected results because average temperature in the water boiler achieved only $22{ }^{\circ} \mathrm{C}$, what is not enough. But we can say CFD simulation it work and can be used for another testing with different fill and different number of pipes.

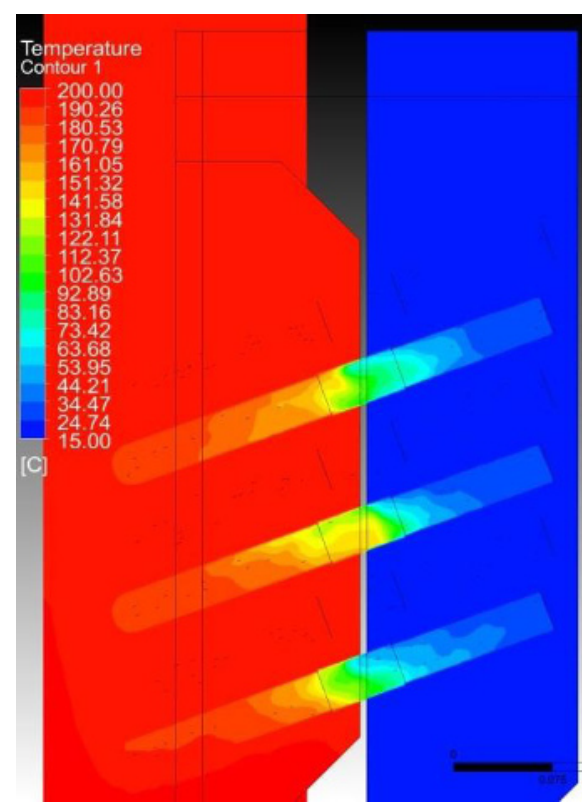

Fig. 9. Results from CFD simulation after $175 \mathrm{~min}$, detail.

\section{Conclusion}

To confirm the correctness of the mathematical model of indirectly heated hot water heater is necessary to verify the measurement.

CFD simulation results will be verified on real models, if the results are consistent with the CFD model, we use a CFD model for further simulations.

\section{Acknowledgement}

This paper was prepared within the project VEGA no. $1 / 1290 / 12$.

\section{References}

1. K. Kaduchová, Diplomová práca (Žilina, 2010)

2. R. Lenhard, J. Jandačka, Colloquium FLUID DYNAMICS Institute of Thermomechanics AS CR, v.v.i., Prague, (2008)

3. M. Čarnogurská, Základy matematického a fyzikálneho modelovania $v$ mechanike tekutín a termodynamike, 176 (2000)

4. P. Nemec, A. Čaja, M. Malcho, Erin 5, 87-90 (2011)

5. P. Nemec, A. Čaja, M. Malcho, Acta metallurgica slovaca conference 1, 159-162 (2011)

6. STN EN 13 229, Vstavané spotrebiče na vykurovanie a kozubové vložky na tuhé palivá

7. Fluent Inc. of ANSYS Inc. FLUENT 6.3, Documentation. User's Guide, (2006)

8. www.cfd-online.com 